erosion rate constant for inorganic and organic-rich sediments where field observations are unavailable.

Section 3 includes six papers on primary production, nutrient fluxes, and mineralization in shallow coastal lagoons of the Baltic Sea. This collection of papers include studies of the significance of microphytobenthos primary production; benthic microbial decomposition and mineralization of organic carbon; and dynamics and controls of benthic fluxes of iron, manganese, methane, nitrous oxide, oxygen, and nutrients. These excellent studies were all conducted in the same geographic area and many of the co-authors overlapped. I was a bit disappointed that the editors did not take the opportunity to provide an integration or synthesis for this section. It would have added considerable to the book. Section 4 contained two papers; one on the effects of plant roots on immobilizing zinc and lead ions in the Tagus estuary (Portugal), and one on the use of the elemental composition of historically distant deposits in reconstructing paleoenvironments along the west coast of Korea.

The final section includes six papers focused on sea level rise and land reclamation case studies from Cameroon, China, and the Wadden Sea. The Cameroon case study is an interesting and quite thorough, albeit speculative, integration of the potential effects of sea level rise on coastal fisheries, including suggestions for adaptation and response. Two papers address the effects of land reclamation in China on sea-level-rise impacts and the potential impacts of sea level rise, sediment supply, and resulting altered current and tide regimes on coastal structures. The two papers on the Wadden Sea "squeeze" (i.e., the loss of space for settlement of finegrained material) reconstruct theoretical sediment type distributions, in the absence of dikes, to explore their impacts, as well as those of continued sea level rise on the lack of mud flats and organic matter in these tidal basins. The final paper uses two land-reclamation case studies from China to describe application of the principles of Integrated Coastal Area Management.

My only disappointment in this otherwise excellent book was that it did not seem to live up to its title that includes reference to "resource management". While there were some movements in that direction in a few of the papers, it did not seem to be the primary focus anticipated in the title. Many of the papers could have taken a step closer to that science/management interface. As a proceedings volume, this one was better than most; peer reviews and careful editing make a positive difference. I recommend this survey of case studies that explore the dynamics of muddy coastal environments to specialists in these areas, as well as to those with a more general interest in how these processes impact use and sustainability of these environments. [d

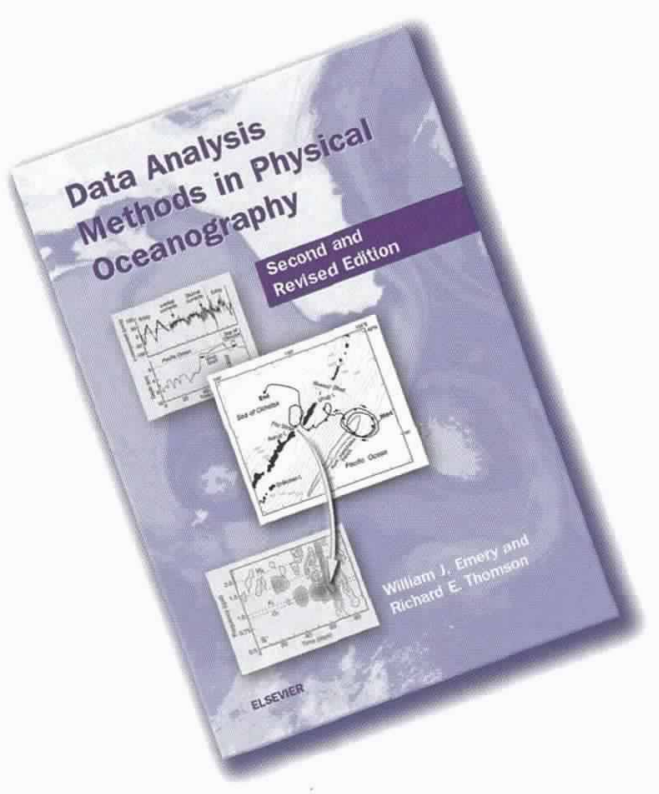

\section{Data Analysis Methods in Physical Oceanography}

\author{
Second, Revised Edition \\ by W.J. Emery and R.E. Thompson \\ Elsevier Science \\ ISBN 0-444-50757-4, 658 pages

\section{Review by \\ Al Plueddemann \\ Woods Hole Oceanographic Institution \\ Woods Hole, Massachusetts USA}

A previous review (Oceanography, 1999, 12[3], 53-54) described the contents of the first edition in detail, and praised the book as the most comprehensive and practical source of information on data analysis methods available to the physical oceanographer. Both the detailed description and the high praise remain applicable to the second edition, which is nearly identical to the first.

The most significant change is that the second edition is available in paperback at about $40 \%$ of the hardcover cost. The lower price should help to get this excellent resource in the hands of more scientists, teachers, and students.

Minor changes in the second edition include the correction of about a dozen typos and other errors, the revision of half a dozen equations with missing or erroneous terms, and several modifications and additions meant to clarify meaning. A few more significant errors in equations, matrices, and tables have also been corrected (most notably in the section on harmonic analysis using the method of least squares). The second edi- 
tion also includes a new appendix that introduces the convolution theorem and describes, mathematically and graphically, time domain "windows" and their use as data filters.

Minor quibbles are that the reproduction quality of photographs has suffered (at least in the paperback edition) and, alas, the text is still not error-free, as indicated by a few typos found during my review.

In sum, this is an excellent, practical text on data analysis, with minor improvements over the first edition, that is now available in paperback at a significant savings over the hardcover version.

\section{Books Undergoing Review:}

\section{Encyclopedia of Ocean Sciences}

Edited by John H. Steele, Karl K. Turekian and Steve A. Thorpe Academic Press

The Diatoms: Applications for the Environmental and Earth Sciences

Edited by Eugene F. Stoermer and John P. Smol Cambridge University Press

Wind Stress over the Ocean

Edited by lan S. F. Jones and Yoshiaki Toba Cambridge University Press

\section{Ocean Circulation and Climate}

Edited by Gerold Siedler, John Church and John Gould Academic Press

\section{Sea Level Rise}

Edited by Bruce C. Douglas, Michael S. Kearney

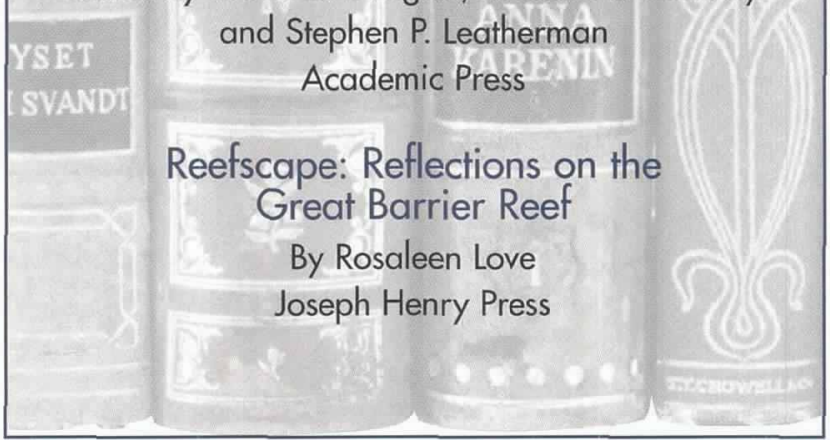

\section{Manuscripł Solicitation:}

A new section entitled Breaking Waves will be appearing in issues of Oceanography beginning in 2002. The purpose of this new section is to provide an outlet for short papers describing novel approaches to multi-disciplinary problems in oceanography. These provocative papers will present findings that are synthetic by design, and have the potential to move the field of oceanography forward or in new directions. Papers should be written in a style that is both concise and accessible to a broad readership. While these papers should be thoughtprovoking for the professional oceanographer, they should also be written in a manner that is engaging for the educated non-professional. As in other sections of Oceanography, we encourage the use of color photographs and figures to help illustrate a paper's main points and add to its aesthetic appeal. Consistent with our effort to publish papers on rapidly advancing topics in oceanography, all submissions to the Breaking Waves section will be given a special fast-track in the peer-review and publishing process. Our goal will be to publish papers no more than two issues (i.e. six months) after their submission. The Associate Editor overseeing the development of Breaking Waves is Charles H. Greene (chg2@cornell.edu), Department of Earth and Atmospheric Sciences, Cornell University. Authors should submit a brief e-mail message to the Associate Editor outlining their ideas for papers prior to actual manuscript preparation. This step will insure that authors receive appropriate feedback prior to investing their time and energy in preparing manuscripts that may be unsuitable for publication in this forum. Correspondence with the Associate Editor and submission of manuscripts should be done electronically whenever possible. File formats for text, figures, and photographs must be consistent with existing style guidelines for Oceanography. 